\title{
ERRATUM
}

\section{Erratum to: Lithium-based ionic liquids as novel lubricant additives for multiply alkylated cyclopentanes (MACs)}

\author{
Zenghong SONG ${ }^{1,2}$, Yongmin LIANG ${ }^{1}$, Mingjin FAN ${ }^{1, *}$, Feng ZHOU ${ }^{1}$, Weimin LIU $^{1, * *}$ \\ ${ }^{1}$ State Key Laboratory of Solid Lubrication, Lanzhou Institute of Chemical Physics, Chinese Academy of Sciences, Lanzhou 730000, China \\ ${ }^{2}$ University of Chinese Academy of Sciences, Beijing 100049, China \\ Received: 11 April 2013 / Revised: 31 May 2013 / Accepted: 14 June 2013
}

(C) The author(s) 2014. This article is published with open access at Springerlink.com

\section{Erratum to}

Friction 1(3): 222-231 (2013)

DOI 10.1007/s40544-013-0019-x

The original version of this article unfortunately contained the incorrect E-mail address of the corresponding author Mingjin Fan on page 222, instead of

farmingjin@licp.cus.cn

It should read

fanmingjin@licp.cas.cn

The online version of the original article can be found at

http://dx.doi.org/10.1007/s40544-014-0066-y

* Corresponding author: Weimin LIU, Mingjin FAN.

E-mail:wmliu@licp.cas.cn, fanmingjin@licp.cas.cn 